\title{
A Gendered Citation Patterns across Political Science and Social Science Methodology Fields
}

\author{
Michelle L. Dion', Jane Lawrence Sumner ${ }^{2}$ and \\ Sara McLaughlin Mitchell ${ }^{3}$
}

\author{
${ }^{1}$ Associate Professor, Department of Political Science, McMaster University, Hamilton, ON, L8S 4M4 Canada. \\ Email:dionm@mcmaster.ca \\ ${ }^{2}$ Assistant Professor and Benjamin E. Lippincott Chair in Political Economy, Department of Political Science, University of \\ Minnesota, Minneapolis, MN 55455, USA.Email:jlsumner@umn.edu \\ ${ }^{3}$ F. Wendell Miller Professor, Department of Political Science, University of lowa, lowa City, IA 52242, USA. \\ Email: sara-mitchell@uiowa.edu
}

\begin{abstract}
Accumulated evidence identifies discernible gender gaps across many dimensions of professional academic careers including salaries, publication rates, journal placement, career progress, and academic service. Recent work in political science also reveals gender gaps in citations, with articles written by men citing work by other male scholars more often than work by female scholars. This study estimates the gender gap in citations across political science subfields and across methodological subfields within political science, sociology, and economics. The research design captures variance across research areas in terms of the underlying distribution of female scholars. We expect that subfields within political science and social science disciplines with more women will have smaller gender citation gaps, a reduction of the "Matthew effect" where men's research is viewed as the most central and important in a field. However, gender citation gaps may persist if a "Matilda effect" occurs whereby women's research is viewed as less important or their ideas are attributed to male scholars, even as a field becomes more diverse. Analysing all articles published from 2007-2016 in several journals, we find that female scholars are significantly more likely than mixed gender or male author teams to cite research by their female peers, but that these citation rates vary depending on the overall distribution of women in their field. More gender diverse subfields and disciplines produce smaller gender citation gaps, consistent with a reduction in the "Matthew effect". However, we also observe undercitation of work by women, even in journals that publish mostly female authors. While improvements in gender diversity in academia increase the visibility and impact of scholarly work by women, implicit biases in citation practices in the social sciences persist.
\end{abstract}

Keywords: gender, citations, sociology of science, political science, sociology, economics, methodology

\section{Introduction}

Academics invest a great deal of energy into understanding factors that explain variance in citations to published research. When making decisions for raises, tenure and promotion cases, grants, and research awards, citations become a natural benchmark for assessing the impact of scholarly work. Journals regularly report their annual impact factor scores as measures of their success. Scholars use a variety of citation measures, including total citation counts, the h-index, the e-index, and Altmetrics. ${ }^{1}$ Accruing citations to one's work can increase the chances for future

Political Analysis (2018) vol. 26:312-327

DOI: $10.1017 /$ pan.2018.12

Corresponding author Sara McLaughlin Mitchell

Edited by

R. Michael Alvarez

(C) The Author(s) 2018. Published by Cambridge University Press on behalf of the Society for Political Methodology. citations through websites that incorporate citations into their search algorithms (e.g. Google).

Authors' note: We thank Amanda Meyers for section membership statistics for the American Political Science Association and Yanna Krupnikov, Michael Alvarez, and the anonymous reviewers for helpful feedback. An earlier version of this paper was presented at the 2017 Annual Meeting of the Midwest Political Science Association. See Dion et al. (2018, doi:10.7910/DVN/R7AQT1) for replication materials.

1 The h-index calculates the number of published papers ( $h$ ) with the same (minimum) number of citations. For example, a scholar with an h-index of 25 has published 25 papers with 25 or more citations to each paper. The e-index is calculated similarly to the h-index but places more weight on highly cited papers. Altmetrics capture the social media and media impact of a published article through such things as tweets, re-tweets, Facebook posts, and coverage in newspaper articles. 
Self-citations can also be accumulating, such that the promotion of one's own work in an article can increase citations to that research in the future (Fowler and Aksnes 2007). ${ }^{2}$ In short, there are many career and financial ${ }^{3}$ benefits that can accrue to scholars who can successfully capture attention in the citation market.

However, research suggests that some scholars are more advantaged in capturing citations than others. Analyses across multiple disciplines confirm the presence of a gender citation gap, whereby male scholars achieve a higher number of citations to their work than female scholars in the same fields. While some subfields' citation networks are male-dominated because there are few female scholars to be cited (a "Matthew effect"), women's research may also be less central in the network of scholarly citations, and a "Matilda effect" can emerge (Rossiter 1993), where women's contributions are less recognized or where women's research findings are attributed to other male scholars. Yet there are differences across academic disciplines suggesting that the context within which female scholars publish can matter for the accruing of scholarly citations. Ferber's (1988) analyses of citation patterns in multiple disciplines suggest that the presence of a critical mass of female scholars could help to eliminate the citation gender gap.

We explore gender citation patterns across three political science journals governed by the American Political Science Association (APSA) or its affiliated organizations ${ }^{4}$ as well as subfield journals that publish methodological research in political science, sociology, and economics. ${ }^{5}$ Following Ferber's (1988) results, we expect that journals in disciplinary fields and subfields with more female scholars will have smaller gender citation gaps. Specifically, we expect work by female scholars to be less likely to be cited in methodological journals compared with nonmethodological journals because quantitative areas of the social sciences are heavily populated by male scholars. At the same time, disciplines with greater gender balance are expected to have smaller gender gaps in citations across their methodological subfields. Further, we hypothesize that female scholars are more likely, than their male colleagues, to be aware of and cite work by women, and that as the proportion of women in a field increases, this gap between men's and women's awareness and citation of women's work will be reduced. Thus, increased diversity in a discipline or subfield should reduce both the "Matthew" and "Matilda" effects. We selected journals in the social sciences that provide variation in representation of women scholars publishing in these outlets (low, medium, and high) to determine if citation practices of all scholars in a research field are influenced by aggregate levels of gender diversity.

We use a broader set of articles than previous studies by using a tool for coding the gender of authors in scholarly studies (Teele and Thelen 2017; Sumner 2018). Our analyses show that female authors are significantly more likely than male authors to cite studies by female authors and that mixed gender teams have statistically similar, but slightly higher odds of citing studies by women compared to male author teams. While this relationship is broadly consistent across disciplines and subfields, we also observe that women have much higher odds than men of citing work by women, and that the odds increase as fields become more male-dominated. The baseline average probability that an article reference will be written by a woman varies based on the proportion of women in the discipline or subfield. Our results show that gender diversity across disciplines in the social sciences and within subfields of political science influences the attention and impact of work by female scholars. Overcoming these citation gaps requires recruitment of more female

2 In an analysis of 1.5 million JSTOR articles published between 1779 and 2011, King et al. (2016) find that men cite their own papers $56 \%$ more than women do. This gap widened over time, with men being $70 \%$ more likely to self-cite in the past two decades of their dataset.

3 Diamond (1986) estimated the effect of a single citation on salary to be between $\$ 50$ and $\$ 1300$. Geraci, Balsis, and Busch (2015) note that women would make $\$ 325,000$ less than men over 25 years based on lower average $h$-index scores.

4 Journals include American Political Science Review, Political Analysis, and Politics \& Gender.

5 Journals include Econometrica, Political Analysis, and Sociological Methods \& Research. 
scholars in the social sciences as well as raising awareness about implicit biases that influence citation decisions in the academic profession.

\section{Research on Gendered Citation Patterns}

We must understand two related issues to detect potential gendered patterns in scholarly citations. First, if male scholars publish more journal articles or books than female scholars, a pattern typically observed in many disciplines, this creates greater baseline opportunities for men's work to capture citations. Second, citations are embedded in academic networks, making it important to examine who is citing whom and whether certain types of scholars are more likely to be cited. In other words, overall citation counts (or counts per article) miss the sociological aspects of how scholars recognize the work of their peers.

We start with a basic question about gendered variance in citations: do women faculty receive fewer citations to their journal articles than male faculty? Several disciplines produce evidence of lower citation levels for female scholars compared to male scholars in the same field including economics (Ferber 1988; Ferber and Brün 2011), ecology (Cameron, White, and Gray 2016), political science (Dion and Mitchell 2012; Maliniak, Powers, and Walter 2013; Mitchell, Lange, and Brus 2013; Roberts, Stewart, and Nielsen 2017), library and information sciences (Håkanson 2005), linguistics and sociology (Leahey, Crockett, and Hunter 2008), and health and natural sciences (Aksnes et al. 2011; Beaudry and Larivière 2016). This is often described as a "Matthew effect" whereby men as the predominant publishers in a field receive more citations, stature, and influence in their disciplines (Rossiter 1993; Reece-Evans 2010: 13). Analyses of citation data in other disciplines suggest either that there are no differences between male and female faculty in terms of citations (total or per article) [public administration (Corley and Sabharwal 2010), sociology (Ward, Gast, and Grant 1992), international relations (Østby et al. 2013), economic history (Di Vaio, Waldenström, and Weisdorf 2012), Spanish science PhDs (Borrego et al. 2010), criminal justice (Stack 2002), forestry and geography (Slyder et al. 2011), in a sample of Danish scientists (Nielsen 2016)] or that female scholars receive more citations per article than their male peers [biochemistry (Long 1992), construction studies (Powell et al. 2009)]. Where gender citation gaps are found, research typically shows that men's willingness to cite their own work at higher rates accounts for some of these observed gaps (Hutson 2006; Maliniak, Powers, and Walter 2013; Ghiasi, Larivière, and Sugimoto 2016).

Citation counts can also be problematic because they can be heavily affected by outliers, they can increase significantly over scholars' careers, and they tend to reward scholars who publish a high quantity of articles. Long's (1992) analysis of productivity and citations in biochemistry raised this issue, pointing to the potential gendered bias that could emerge if female scholars publish fewer articles on average than their male peers, yet have higher citations per article. The h-index was created to address some of these problems, capturing the total number of articles that have accrued that number of citations. ${ }^{6}$ Yet even the h-index came under scrutiny for being biased against female faculty (Symonds et al. 2006; Nosek et al. 2010; Geraci, Balsis, and Busch 2015). Self-citations can increase the $h$-index score, behavior that is more likely for male scholars (Fowler and Aksnes 2007; King et al. 2016). Hopkins et al. (2013) found that women in biochemistry, water resources, economics, and anthropology had $\mathrm{h}$-indices that were one to four points smaller on average than their male peers. In a study of nearly 1700 social work faculty, a field where $65 \%$ of faculty are women, Carter, Smith, and Osteen (2017) showed that men had 3.86 higher h-index scores than women across all ranks, with a larger gap at the full professor rank. Cameron, White,

6 The h-index sets a minimum number of citations across a series of journal articles. If a scholar has two highly cited pieces with over 100 citations per article, but 10 other articles with zero citations, the low h-index score (2) would capture the effect of the outliers. 
and Gray (2016) observe in ecology, where women have earned more than 40\% of PhDs since 1993, that men have higher $\mathrm{h}$-indices and cite their work more often than women.

Most of these studies seek to account for the variance in scholars' citation scores by examining the output over a scholarly career and citation patterns over time. Yet while the aggregate differences in citation counts or h-indices tells us that potential gender biases exist, it is difficult to know if this occurs simply because men publish and cite themselves more than women or if scholars systematically fail to cite relevant work by women in their field (or both). In contrast to the "Matthew effect" that raises the stature and influence of research by male scholars, the "Matilda effect" is very pernicious because this dynamic omits work by women from articles, ${ }^{7}$ textbooks (Cassese, Bos, and Duncan 2012), and course syllabi (Hardt et al. 2017; Colgan 2017). Knobloch-Westerwick, Glynn, and Huge (2013) tested for the "Matilda effect" by randomly assigning male or female names from the U.S. census database to abstracts that were submitted to a national communication studies conference; 243 graduate students in the field assessed the scientific quality of the abstracts. They found that abstracts randomly assigned male authors were scored higher on the quality scale by both male and female graduate students. Furthermore, if the topic of the abstract was a more male-centric topic, the work was perceived to have greater scientific quality. Much of the variance in these research quality scores could be explained by the participants' underlying gender norms. These kinds of implicit biases can influence the value that scholars place on academic research and hence influence citation practices.

Ferber, an economist, investigated these sociological patterns by focusing on who cites whom in academic research. Her 1986 study examined citations in the Journal of Economic Literature and discovered that scholars were more likely to cite research by scholars that share their biological sex. To see if these findings generalized beyond labor economics, another article (Ferber 1988) expanded the analysis to multiple journals across several academic disciplines, including U.S. and Canadian academic journals in economics, mathematics, psychology, and sociology. Articles published by one or more women were combined with a random sample of articles by authors based on publication lists in the Journal of Economic Literature, Mathematical Abstracts, Psychological Abstracts, and Sociological Abstracts to construct the percentage of citations to work by male and female scholars by discipline. This expanded dataset confirms Ferber's earlier findings that male scholars are more likely to cite the work of other male scholars, while female scholars also cite the work of female peers more frequently. Among male authors, the gender gap ranged from $15 \%$ in development psychology to less than $5 \%$ in mathematics. For example, in development psychology, $67 \%$ of the citations in articles written by men are to research by men, while $52 \%$ of citations in female authored articles cite research by men, generating a $15 \%$ gap. Yet in fields in which the gap is small, men and women authors cite mostly male authors. In mathematics, $98 \%$ of works cited by men are written by men, while $94 \%$ of works cited by female authors are written by men. In development psychology and sociology, on the other hand, Ferber found that research by women constituted $7.5-18.1 \%$ of male authors' citations and $15.8-29.1 \%$ of female authors' citations. Given the relatively larger percentage of female scholars in psychology and sociology, ${ }^{8}$ both male and female scholars' decisions about what work to cite are influenced by the overall representation of women in the discipline. "The 'citations gap' appears to decrease

7 Women might not only accrue fewer citations to their work, they can also become less central in their discipline's citation network. Analysing over 3,000 journal articles in every first and third issue for twelve political science journals from 1980 to 2006, Maliniak, Powers, and Walter (2013) find that women's articles are systematically less central in the political science article citation network and that authors of the most influential articles cite women's work less frequently. This behavior helps to account for the underrepresentation of women in international relations graduate syllabi as well, with women assigning more research by female scholars and assigning their own research less often than their male peers (Colgan 2017).

8 Ferber (1988) reports the percentage of women in developmental psychology as $48 \%$ and the percentage of women in sociology as $34 \%$; this compares to $19 \%$ in labor economics, $12 \%$ in finance economics, and $13 \%$ in mathematics. 
as the proportions of women in the field and of articles written by women increase, in part because men are then more likely to cite work by women (Ferber 1988: 86). ${ }^{9}$

Mitchell, Lange, and Brus (2013) utilize Ferber's approach to match the biological sex of each author with the sex of each author cited in the bibliography entries $(N=3,414)$ for 57 articles published in International Studies Quarterly (ISQ) and International Studies Perspectives (ISP) in 2005. The analyses show that the proportion of citations of women's research is three times higher for female authors compared to male authors in ISQ and twice as large for female authors in ISP. Dion and Mitchell (2012) conduct similar analyses for 2005 journal issues for Conflict Management and Peace Science (CMPS), Journal of Conflict Resolution (JCR), and Political Analysis. Female authors in CMPS are three times more likely to cite the work of other female scholars in comparison to male authors, an effect that is very close to what Mitchell, Lange, and Brus (2013) reported for ISQ. ${ }^{10}$ In Political Analysis, the citation gender gap is even larger with only $3 \%$ of total citations in male authored papers referencing research by female authors. This compares to $10 \%$ of citations by female authors to the research of other female authors. These analyses demonstrate that female political scientists reference more research by women in the discipline than their male colleagues and that such patterns are especially likely in areas of political science that are populated heavily by male scholars.

While a variety of factors could explain the gender gap in academic citations, in fields where women make up a small minority of the profession, their work may simply be less visible relative to the majority group. Women might need to reach a critical mass before a systemic change in citation patterns can occur. Ferber and Brun's (2011) study suggests that the gender gap in citations has decreased, especially in the field of labor economics, where women constitute close to one third of scholars in the field. In the general field of economics, where women are still a relatively small group, however, the gender gap in citations is larger. Our review of citation studies across disciplines shows some fields where the gap is large (e.g. political science, library and information sciences, natural sciences), others where it is negligible (e.g. public administration, sociology, economic history), and others where women are advantaged (e.g. biochemistry). ${ }^{11}$ Fields where the gender gap has been reduced tend to be populated by higher percentages of female scholars, although some female-dominated disciplines like social work still witness higher citation rates for male scholars. This shows that while the "Matthew effect" can be attenuated as more women scholars populate an academic discipline, the "Matilda effect" can produce a persistent gender gap in citations. ${ }^{12}$ Therefore, we include in our sample publications from political science subfields with high proportions of men (political methodology) and women (politics and gender) as well as the top methodological publications in sociology, political science, and economics, all social sciences with different gender distributions. In the social sciences, a preoccupation with

9 If we could observe the citation gender gap across all academic fields, we would likely find a nonlinear relationship with percentage of women scholars in a field. In highly male populated areas like math, the gap is small. As the percentage of women in a field increases, the citation gender gap would increase and then decrease once women scholars reached a critical mass. The three disciplines we examine (economics, political science, and sociology) represent low, medium, and moderately high levels of representation of women scholars. But given that each discipline has reasonable representation of women, we expect the citation gender gap to be largest in economics and smallest in sociology; similar patterns are expected across political science journals with the smallest citation gender gap expected in the journal affiliated with the most female representative area of APSA (Politics \& Gender). Our analyses focus on the probability of authors citing work by same sex authors rather than the aggregate citation gap based on overall citations in a discipline or research area.

10 In the Journal of Conflict of Resolution (JCR) in 2005, only one article was published by a female (only) author (Beth Simmons) and there were no statistically significant differences in the patterns of her citations compared to other JCR authors that year.

11 Leahey, Beckman, and Stanko (2017) show that interdisciplinary research is associated with lower productivity and higher visibility (citations), but that the variance around citations is larger than for traditional disciplinary work. Female scholars are often attracted to working in interdisciplinary fields, which could influence the impact of their research programs.

12 In other words, women's research will be cited more frequently in disciplines with higher gender diversity, but men's research may still be treated as the most central or important research in those areas. The citation gender gap would diminish but not reach zero in the presence of implicit gender biases in the attribution of ideas. 
research methodologies that began with behavioralism in the 1950s continues to shape the development of disciplinary practices and research. Even those critical of political science's trend toward specialization acknowledge that scholars using sophisticated methodologies serve as the discipline's gatekeepers and trend setters (Mead 2010, 454). By using a larger number of journal articles than previous studies and probabilistic methods for identifying authors' gender (Teele and Thelen 2017; Sumner 2018), we shed light on how the representation of women in research areas influences gendered citation patterns.

\section{Data and Analyses}

We analyze a dataset of article references for all articles published between 2007 and 2016 in three political science journals and three social science methodology journals. ${ }^{13}$ These comparisons seek to maximize variation in two ways. First, we compare citation patterns within political science, focusing on the highest-ranked flagship research journal of the American Political Science Association (APSA, American Political Science Review, APSR) and the journals (Political Analysis, PA and Politics \& Gender, $P \& G$ ) sponsored by APSA-affiliated organizations with the lowest and highest levels of gender representation (the Society for Political Methodology [aka, Polmeth] and Women and Politics organized APSA section). As of August 2017, the Political Methodology section (which is a subset of Polmeth membership) had 472 members of whom $79.7 \%$ self-identified as male, while the Women and Politics section had 330 members of whom $91.7 \%$ self-identified as female (APSA 2017).${ }^{14}$ Of the 213 APSA members who identified methodology as their primary field of study, 83.57\% also self-identified as male (APSA 2017).

Polmeth governs PA and the APSA Women and Politics section governs Politics \& Gender. While the APSR has a strong history of being one of the most cited and leading journals in the discipline, $P A$ and $P \& G$ are well-cited and highly ranked journals in their respective fields (see Appendix for impact metrics). The editorial leadership of these journals tracks closely with those of the discipline or field. The APSR has not had any female editors between 2007 and 2017, though Associate Editors or Co-Editors (3-8 per year) have been between $25 \%$ and $67 \%$ female (see detailed tables in Appendix). Between 2007 and 2016, the Editorial Board was 36-43\% female, similar to overall APSA membership. In 2017, APSR had a male editor, six Associate Editors of whom only $33 \%$ were female, and 78 Editorial Board members of whom $67 \%$ were female. Since $2007, P A$ has only had one female Editor who was part of a three-member editorial team in the one year in which there were no Associate Editors. Typically, one of the three (or four) Associate Editors is a female scholar, which is greater than the percentage of female methodologists according to APSA section membership or primary field. The PA Editorial Board ranges between 16 and $28 \%$ female, which is more consistent with membership or field identification. In contrast to $A P S R$ and $P A, P \& G$ is led by female scholars, including all Editors, $75-100 \%$ of Associate Editors, and $86-89 \%$ of Editorial Board members. The distribution of editorial roles by gender in these political science journals is consistent with gender distributions in organizational membership and self-identified primary field of study. This variation, including a flagship research journal as well as the journals associated with the two least gender diverse subfields (one dominated by men, the other by women), will help us evaluate the hypothesis that overall citations of female scholarship will be higher and gendered citation gaps lower in subfields with more female scholars.

Given that women constitute a clear critical mass in the politics and gender area, we expect female, male, and mixed gender authors to be similarly likely to cite work by women in Politics \& Gender. Political methodology is the APSA section with the highest proportion of male members and thus we expect to confirm earlier analyses of Political Analysis, which show a clear gender gap

13 See Dion, Sumner, and Mitchell (2018) for the replication materials.

14 The APSA Political Methodology section is only one subset of members of the Society for Political Methodology. Other Society members join directly or through their membership with the European Political Science Association (EPSA). 
in citations (Dion and Mitchell 2012). We anticipate that APSR will fall somewhere in the middle, given that it represents political science research broadly; $37.5 \%$ of APSA members self-identify as female (APSA 2017). Such journals are charged with publishing works from all fields of political science but they often fail to publish research in topical areas or methodological approaches associated with higher concentrations of female scholars (Teele and Thelen 2017, 435-440).

Second, we compare citation patterns across the top-ranked methodology journals in three social sciences that share many research methodologies but experience different disciplinary gender distributions: economics (Econometrica), political science (PA), and sociology (Sociological Methods \& Research, SMR). ${ }^{15}$ While methodological subfields are likely to be male-dominated in general, the gender gap is likely smaller in disciplines with greater gender diversity, such as sociology. In 2013 , only $24 \%$ of economists were female, compared to $32 \%$ of political scientists and $52 \%$ of sociologists (Hur et al. 2017). ${ }^{16}$ The gender distribution within disciplines is also reflected in the gender distributions of editorial team membership across the methodology journals. Although both Econometrica and SMR have had male Editors or Co-Editors between 2007 and 2017, the larger Editorial Board (or Associate Editors, as they are named in Econometrica) is about $7-21 \%$ female in SMR and $4-16 \%$ female in Econometrica (see Appendix, Table A5). ${ }^{17}$ Therefore, we expect the odds of female authors to cite work by women to be higher in economics (compared to mixed gender or male authors), moderate in political science (PA), and the difference to be smallest among sociology authors (SMR). These analyses give us a first look at how the distribution of women in a research area influences the sociological processes by which scholars make citation choices.

\subsection{Authors' Genders in Sample Journals}

Using bibliographic data from the Web of Science for all articles published between 2007 and the end of 2016 in the journals described in the previous section, we assigned genders to authors of articles. ${ }^{18}$ Each article's first five author(s) are coded as being all male, all female, or mixed gender (Table 1). The distribution of gender of author(s) for $P A$ and $P \& G$ are consistent with their membership. One or more men wrote approximately $75 \%$ of $P A$ articles, and one or more women wrote $78 \%$ of $P \& G$ articles. The distribution of authors for APSR is not quite so skewed, though it looks more like that of $P A$ than $P \& G$ with $70 \%$ of articles written by male only authors. ${ }^{19}$ Among methodology journals, Econometrica has the highest percentage of male only author teams (77\%), while SMR has the lowest (65\%).

15 See Tables A1 and A2 in the Appendix for detailed impact metrics.

16 Gender representation also varies by rank, with evidence of modest progress in economics and political science and a steady state in sociology. In economics, 31\% of assistant professors are women versus only $15 \%$ of full professors (Flaherty 2016). For political science (PhD granting departments), women constitute $39 \%$ of assistant professors and $20 \%$ of full professors (Mitchell and Hesli 2013). In both economics and political science, the percent of incoming PhD classes in 2013 that were female were modestly higher than those in 2003, but still only $36 \%$ and $46 \%$ respectively. By comparison, in 2003 $65 \%$ of incoming PhD students in sociology were female, and in 2013,60\% were female (Hur et al. 2017).

17 Econometrica has Co-Editors, while SMR does not.

18 We used genderizeR (Wais 2016; Wais, VanHoudnos, and Ramey 2016) and the genderize.io API to estimate the probability that an author name is female, assigning female to those with probability $>0.7$ and male to those with probability $<0.3$. We hand-coded 282 author names (including duplicates), or about $7.6 \%$ of the total sample. When Teele and Thelen (2017) hand-checked genderize.io gender predictions for 10 political science journal authors for more than a decade, they found that fewer than $2 \%$ of predictions were incorrect, with a tendency to overestimate the probability that an author was female. This suggests that if there is bias in our gender coding, it overestimates the number of article and reference authors who identify as female, and our analyses may understate the degree of gender bias. Before 2007, bibliographic sources did not always or consistently include the first names of article authors nor those of reference authors. The search included the following document types: article, editorial material (including special issue articles), proceedings papers (a research article previously presented at a refereed conference), letters, and corrections. It excluded reviews, book reviews, and biographical items. Items of any type with no references and articles with anonymous authors were excluded. See Appendix for additional explanation of the data collection process and sample characteristics.

19 A recent analysis that used a slightly different sample (i.e., different years and all authors) and calculation (percentage of all authors rather than by article) estimated that $23.4 \%$ of all APSR authors between 2000 and 2015 were female (Teele and Thelen 2017). 
Table 1. Distribution of author genders by article, 2007-2016.

$\begin{array}{ccccc} & \text { Male only authors } & \text { Female-only authors } & \text { Mixed gender author team } & \text { Total } \\ \text { APSR } & 324 & 67 & 73 & 464 \\ & 69.83 \% & 14.44 \% & 15.73 \% & 100 \% \\ \text { P\&G } & 27 & 266 & 47 & 340 \\ & 7.94 \% & 78.24 \% & 13.82 \% & 100 \% \\ \text { PA } & 220 & 8 & 67 & 295 \\ & 74.58 \% & 2.71 \% & 22.71 \% & 100 \% \\ \text { Econ. } & 465 & 25 & 114 & 604 \\ & 76.99 \% & 4.14 \% & 18.87 \% & 100 \% \\ \text { SMR } & 153 & 19 & 63 & 235 \\ & 65.11 \% & 8.09 \% & 26.81 \% & 100 \% \\ \text { Total } & 1,189 & 385 & 364 & 1,938 \\ & 61.35 \% & 19.87 \% & 18.78 \% & 100 \%\end{array}$

Source: Authors' coding of Web of Science bibliographic data. One article in Politics \& Gender with an anonymous author was not coded. See the Appendix for sample characteristics.

\subsection{Analysing Citation Patterns Within and Across Disciplines}

To capture who cites whom, we used the Web of Science to gather all references for the articles published in these five journals since $2007 .^{20}$ The result is a dataset of nearly 54,000 cited references, of which we retrieved complete bibliographic information and coded the gender of the first five authors of a reference for $87.2 \% .{ }^{21}$ We then code our primary dependent variable of interest: whether reference authors are male only, female only, or mixed gender. Table 2 includes the distribution of this variable by journal, which varies in ways consistent with the gendered distribution of scholars in each field or subfield. While $57.8 \%$ of references in $P \& G$ are to work by all female author teams, only $4.4 \%$ and $5.5 \%$ of references in Econometrica and $P A$ respectively are to work by women only.

Following the methodology used elsewhere (Ferber 1988; Mitchell, Lange, and Brus 2013), we regress the gender of the reference authors on the gender of the original article authors. We dichotomize the reference author gender into those references written only by women compared to those by men or mixed gender author teams. To compare the strength of the relationship between article author gender and reference gender by journal, we first estimate separate models by journal to see if the varying representation of women in these political science research areas and social science disciplines influences the degree to which we observe a gender citation gap. These logistic regressions are estimated with robust errors clustered by article. Then, for comparison, we also estimate a model that pools all the references together, with fixed effects by journal and robust errors clustered by article.

The results are presented in Table 3. We see that female authors are significantly more likely to cite work by female scholars in four of the five journals in our sample (and in the pooled model). The journal fixed effects show differences across research areas. Politics \& Gender articles cite

20 See fn. 18 for criteria used in Web of Science searches. We used rcrossref (Chamberlain et al. 2016) and the Crossref API to retrieve complete author data for references with DOI information, and the Google Books API to retrieve complete author data for references with titles not included in the Crossref API. Excluded references are those with organizational or anonymous authors or with failed automated search retrieval. See the Appendix for a detailed explanation of the data collection process.

21 The 13\% of reference names that did not generate a prediction are most likely references with organizational authors (e.g., governmental white papers or newspaper articles) or authors who use initials (e.g., V.O. Key) or have East Asian names. 
Table 2. Distribution of reference author genders, 2007-2016.

\begin{tabular}{|c|c|c|c|c|c|c|}
\hline & $\begin{array}{c}\text { Total } \\
\text { reference } \\
\text { with } \\
\text { complete } \\
\text { information }\end{array}$ & $\begin{array}{c}\text { References } \\
\text { with all } \\
\text { authors } \\
\text { coded (\%) }\end{array}$ & $\begin{array}{c}\text { Male } \\
\text { only ref. } \\
\text { authors }\end{array}$ & $\begin{array}{l}\text { Female } \\
\text { only ref. } \\
\text { authors }\end{array}$ & $\begin{array}{c}\text { Mixed } \\
\text { gender } \\
\text { ref. } \\
\text { author } \\
\text { team }\end{array}$ & Total \\
\hline$A P S R$ & 19,014 & $\begin{array}{l}15,648 \\
82.3 \%\end{array}$ & $\begin{array}{c}11,617 \\
74.24 \%\end{array}$ & $\begin{array}{c}2,203 \\
14.08 \%\end{array}$ & $\begin{array}{c}1,828 \\
11.68 \%\end{array}$ & $\begin{array}{c}15,648 \\
100 \%\end{array}$ \\
\hline$P \& G$ & 7,180 & $\begin{array}{c}5,894 \\
82.09 \%\end{array}$ & $\begin{array}{c}1,649 \\
27.98 \%\end{array}$ & $\begin{array}{c}3,405 \\
57.77 \%\end{array}$ & $\begin{array}{c}840 \\
14.25 \%\end{array}$ & $\begin{array}{l}5,894 \\
100 \%\end{array}$ \\
\hline$P A$ & 7,475 & $\begin{array}{c}5,891 \\
78.81 \%\end{array}$ & $\begin{array}{c}4,650 \\
78.93 \%\end{array}$ & $\begin{array}{c}322 \\
5.47 \%\end{array}$ & $\begin{array}{c}919 \\
15.6 \%\end{array}$ & $\begin{array}{l}5,891 \\
100 \%\end{array}$ \\
\hline Econ. & 14,570 & $\begin{array}{l}10,869 \\
74.6 \%\end{array}$ & $\begin{array}{c}9,226 \\
84.88 \%\end{array}$ & $\begin{array}{c}475 \\
4.37 \%\end{array}$ & $\begin{array}{c}1,168 \\
10.75 \%\end{array}$ & $\begin{array}{c}10,869 \\
100 \%\end{array}$ \\
\hline$S M R$ & 5,667 & $\begin{array}{c}4,053 \\
71.52 \%\end{array}$ & $\begin{array}{c}2,937 \\
72.46 \%\end{array}$ & $\begin{array}{c}347 \\
8.56 \%\end{array}$ & $\begin{array}{c}769 \\
18.97 \%\end{array}$ & $\begin{array}{l}4,053 \\
100 \%\end{array}$ \\
\hline
\end{tabular}

Source: Authors' coding of Web of Science bibliographic data. See Appendix for distributions by journal and year.

female authors at the highest rate, followed by APSR (baseline category), and Political Analysis. Among methodology journals, Econometrica articles cite the fewest female authors, followed by Political Analysis, and SMR. Even though all three of these areas are publishing methodological

Table 3. Logistic Regression Estimates: Gender of references and author teams.

\begin{tabular}{|c|c|c|c|c|c|c|}
\hline & APSR & P\&G & $P A$ & Econ. & SMR & Pooled \\
\hline \multicolumn{7}{|c|}{ Article author team gender } \\
\hline Female only & $\begin{array}{c}0.99 \\
(0.16)\end{array}$ & $\begin{array}{c}0.53 \\
(0.12)\end{array}$ & $\begin{array}{c}0.42 \\
(0.38)\end{array}$ & $\begin{array}{c}1.14 \\
(0.22)\end{array}$ & $\begin{array}{c}0.76 \\
(0.28)\end{array}$ & $\begin{array}{c}0.86 \\
(0.10)\end{array}$ \\
\hline Mixed & $\begin{array}{c}0.21 \\
(0.13)\end{array}$ & $\begin{array}{l}-0.15 \\
(0.16)\end{array}$ & $\begin{array}{c}-0.08 \\
(0.16)\end{array}$ & $\begin{array}{c}0.07 \\
(0.14)\end{array}$ & $\begin{array}{c}0.06 \\
(0.18)\end{array}$ & $\begin{array}{c}0.11 \\
(0.08)\end{array}$ \\
\hline
\end{tabular}

Journal fixed effects (reference category $=A P S R$ )

$P \& G$

$P A$

Econ.

$S M R$

$-0.47$

(0.10)

$\begin{array}{lcccccc}\text { Constant } & -2.07 & -0.01 & -2.84 & -3.18 & -2.46 & -2.02 \\ & (0.05) & (0.11) & (0.09) & (0.06) & (0.10) & (0.05) \\ \text { Pseudo } R^{2} & 0.0253 & 0.0162 & 0.000726 & 0.0105 & 0.00774 & 0.219 \\ \text { Null LL } & -6359 & -4007 & -1249 & -1951 & -1185 & -18566 \\ \text { LL } & -6198 & -3942 & -1248 & -1931 & -1175 & -14509 \\ \text { Clusters } & 464 & 332 & 295 & 604 & 232 & 1927 \\ \text { Observations } & 15,648 & 5,883 & 5,891 & 10,869 & 4,053 & 42,344\end{array}$

Robust standard errors in parentheses. The dependent variable equals one when a bibliography citation was authored by females (only). 

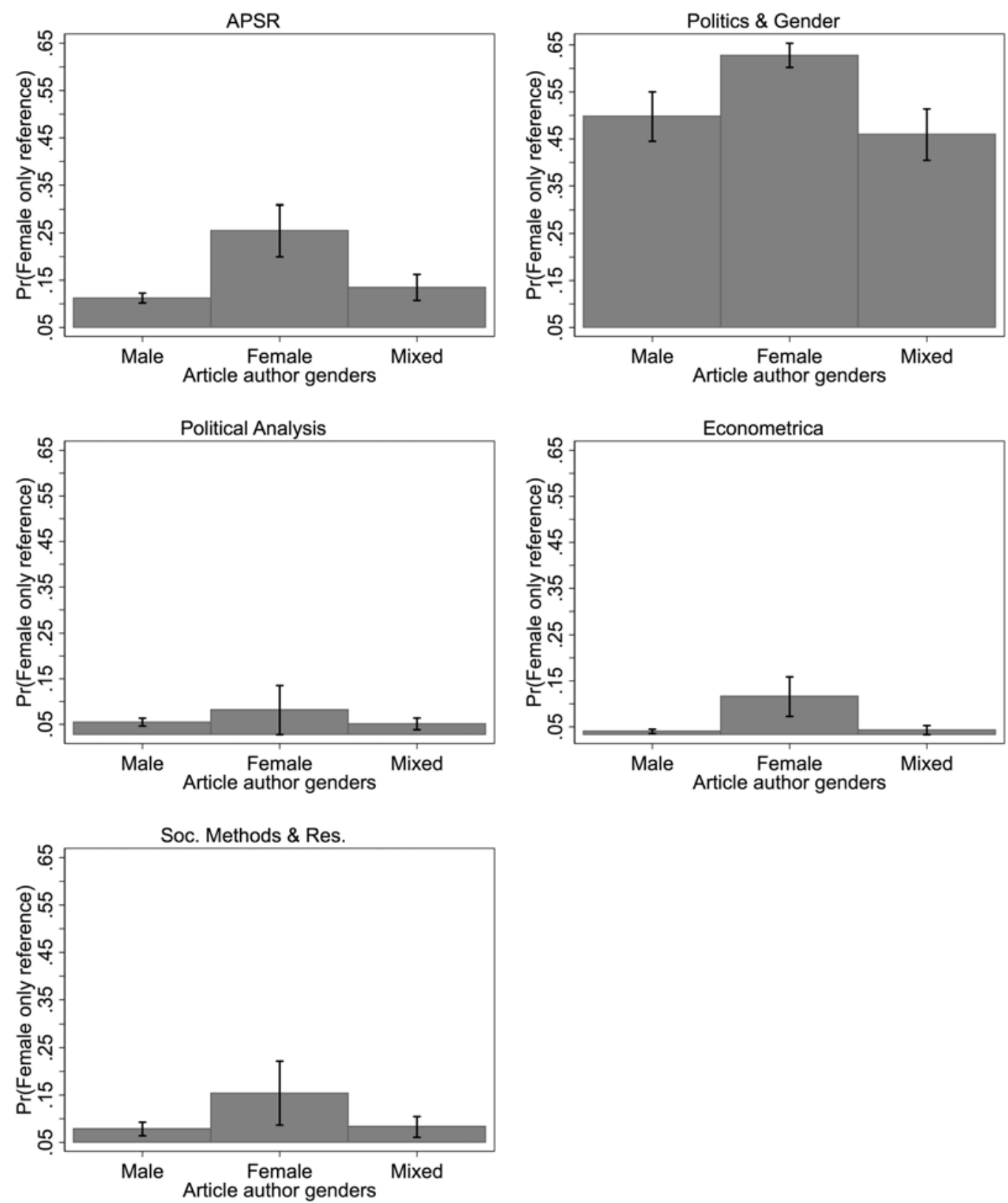

Figure 1. Predicted probability (with 95\% confidence intervals) of citing a female-only reference. Note: Based on separate models in Table 3.

research and draw upon work in other disciplines, there are still noticeable differences across fields, which is consistent with varying degrees of women's representation in the fields.

This is best illustrated in Figure 1, which plots the predicted probabilities of a reference having only female authors by journal and article author team gender. While women have the highest probability of citing work by other women in $P \& G$, there is still a sizable gap in terms of how men and mixed gender teams cite work by women in this research area. Female authors have a 0.63 predicted probability of citing work by women, while the predicted probability of citing work by women for men is 0.50 and for mixed teams is 0.46 in the journal. By comparison, the three methods journals have lower probabilities of citing work by female authors than either a gender journal in a female-dominated field $(P \& G)$ or a general disciplinary flagship journal (APSR), due primarily to the predominance of work by men in these research subfields. In $P A$, the predicted 


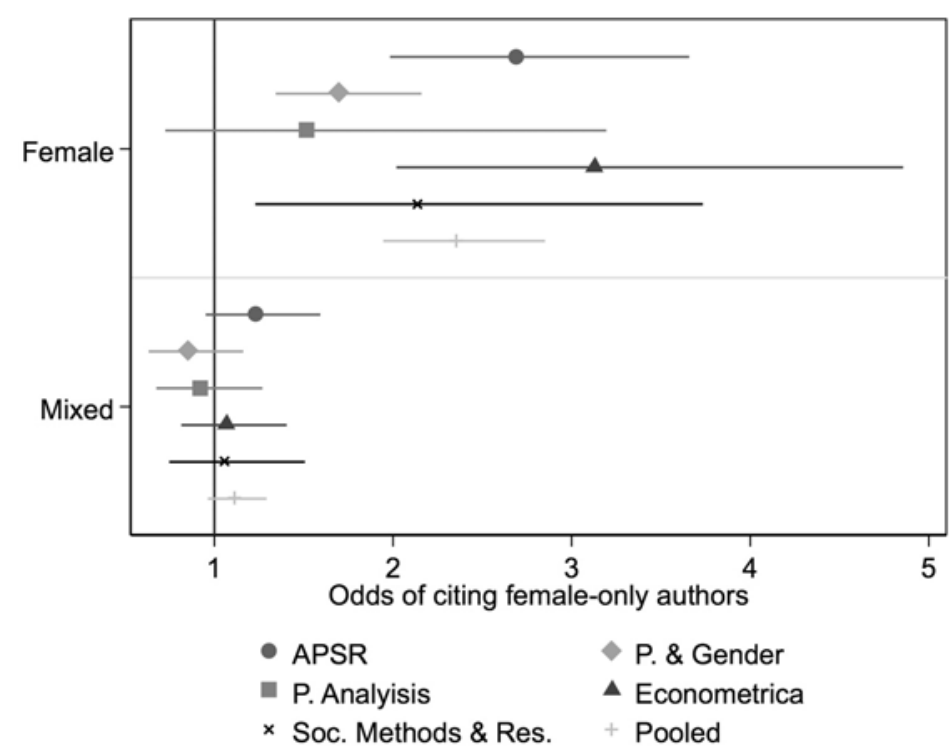

Figure 2. Odds ratios (with 95\% confidence intervals) for models of female-only references by journal. Note: Based on models in Table 3.

probabilities that male authors and female authors will cite work by women are 0.05 and 0.08 respectively, which situates $P A$ between the predicted probabilities of citing work by women for all male and all female author teams in Econometrica (men: 0.04 and women: 0.12) and SMR (men: 0.08 and women 0.15 ). In addition, the gender citation gaps are relatively smaller in these subfields with fewer women than the large gap in the probabilities observed in $P \& G$ or APSR. Much like Ferber (1988) observed a small citation gender gap for mathematics, areas of the social sciences with mostly male scholars also produce articles with few citations to women's research and a smaller citation gender gap. On the other hand, the gap between female authors citing work by women and male/mixed authors is larger for APSR, consistent with "Matilda effects" for the field's flagship journal. Female authors in the APSR have a 0.25 predicted probability of citing work by women, while that probability is only 0.11 among male authors and 0.13 among mixed gender teams. The proportion of women in a subfield or discipline is clearly associated with gendered citation practices for all scholars working in those fields. While greater gender representation in an academic field improves attribution of ideas to work by women scholars, the citation gender gap persists, providing evidence in favor of the "Matilda effect". Even when women constitute the majority of scholars in a research area and the editors and editorial board members of a journal like $P \& G$, the probability of men citing work by women scholars is 0.13 lower than their female author peers.

Figure 2 illustrates the odds ratios of article author genders relative to male only author teams across models in Table 3. The figure shows that female-only author teams have significantly higher odds of citing work written only by women, compared to male only author teams. By comparison, when women co-author with men on mixed gender author teams, they are not significantly more likely to cite references with female-only authors than male only article authors. This pattern mirrors previous results that showed mixed gender teams adopting citation practices like all male author teams (Mitchell, Lange, and Brus 2013). At the same time, the tendency for female authors to be more likely to cite other women is higher among authors of articles in Sociological Methods \& Research than female authors in $P A$, which is expected given the differences in the proportion of women in each discipline. The results show that citation practices are influenced by gender diversity. While methodological approaches in the social sciences share many similarities and build upon research in other disciplines, the centrality of women's work varies significantly with 
respect to citations in the flagship methodology journals in economics, political science, and sociology.

Analyses in the Appendix show that our results are robust when controlling for other factors that influence citation decisions. First, we present results for specifications where the dependent variable is recoded to combine female-only and mixed gender authored references, compared to male only references. The results are similar to the analyses reported above. Second, given that our dataset covers a ten-year span, we also test for temporal changes in our results. This is especially important given the emergence of mentoring programs for women in research fields that include authors of the journals that we examine..$^{22}$ In the Appendix, we present the proportion of article authors (first five authors) that are male or female in each journal over time. Of the journals in our sample, only APSR appears to have a steady increasing proportion of authors that are female over the decade of the sample. Next, we examine the percentage of the first five authors of each coded reference that is male or female by journal and year. If women's representation is increasing in the corpus of available research to be cited, then we might also expect the proportion of reference authors that is female to increase as well. While the proportion of reference authors that are female seem to increase slightly in APSR and Political Analysis in the last few years of the data, we see few dynamic patterns overall. We also estimate the models in Table 3 including fixed effects for each year in our sample. Our primary findings hold; in all journals except Political Analysis, female authors are significantly more likely to cite work by female authors compared to both men and mixed gender author teams. If indeed women were, on average, more likely to be cited with each additional year due to their growing representation in the corpus of available references, we would expect the fixed effects to gradually move away from the baseline category, 2007. Instead, the results indicate that while some years may deviate significantly from 2007 , overall there is no trend in the coefficients toward higher probabilities of citing work by female authors in any of the journals. The confidence intervals for the fixed effects mostly overlap as well, suggesting few temporal changes in citation practices. We also estimated the models in Table 3 separately for the first and most recent years for each journal included in the sample. The results are available in the Appendix (Table A11). In most comparisons across years for the same journal, the coefficients are substantively and statistically similar. ${ }^{23}$ In summary, we have no reason to believe that the pooled results that we present change in any significant way between 2007 and 2016.

Third, we estimated models controlling for the earliest publication by a member of the author(s) to account for potential cohort effects since older authors might have higher baseline probabilities of being cited. We coded the author teams into one of 5 cohorts based on the oldest author: 2007-2016 (reference category in analysis), 1997-2006, 1987-1996, 1977-1986, and 1967-1976. We also estimated our models using time since first publication, measured in years from zero through 50. The coefficients for the gender of the author team (female only, mixed) are not substantively different from those presented in Table 3 when we include cohort or time since first publication variables (see Appendix, Tables A12 and A13). We still find that women cite work by women at significantly higher rates than male or mixed gender author teams. ${ }^{24}$

22 For example, Visions in Methodology (VIM) conferences began in 2008 and provide mentoring to women in political methodology who could publish research in Political Analysis (see Dion 2014 for an overview of VIM).

23 We also estimated the model in Table 3 for each journal separately by year. However, many journals have so few female-only authored articles that the models often fail to generate estimates. For example, in 2007, 2010, 2012, 2013, and 2105, there were no articles published in Political Analysis written by female-only author teams. Where we can estimate models, the results do not suggest that the gender dynamics in citation practices have shifted over the decade of our sample.

24 We also estimated models that included an interaction between time since first publication (in years) and author team genders. We find that the citation gap (or likelihood of citing work by female scholars compared to male scholars) for female-only author teams (compared to male only author teams) increases significantly as the number of years since first publication for a member of the team increases, but only for Econometrica and SMR. 
Finally, we seek to determine if the citation gender gap is likely driven by women overciting work by other women, men underciting work by women, or both. Two tables in the Appendix (A6 and A7) provide information about the proportion of female authors and the proportion of females cited in the references. The percentage of females cited in the references for each journal is lower than the percentage of female authors, suggesting that women's work in general is not being overcited in these journals. Even in a journal with a majority of female authors like $P \& G$, the gap between female authors ( $82 \%$ ) and female references (61\%) is fairly large. Given the gender dynamics we see when pairing author to reference citations (Table 3), this suggests that most of the citation gap is driven by men and mixed author teams underciting work by women rather than women overciting work by other female scholars.

\section{Conclusion}

Scholars receive many benefits when other scholars cite their research in published studies, including recognition for their work and increased chances for grant funding, raises, and successful promotion and tenure decisions. Yet these benefits are not equally distributed in most academic disciplines. Gender citation gaps are prevalent in academia, suggesting that female scholars do not receive the same stature and influence from their published research relative to their male peers. Our study examines authors' choices for whom to cite in journal articles in several political science, economics, and sociology journals from 2007-2016, with an emphasis on the overall gender diversity of the discipline or subfield. We hypothesize that women's research will be cited more often in areas that have greater gender diversity, but that a "Matilda effect" may persist, especially if articles and books by women do not form the central core of knowledge in academic fields. In addition to receiving fewer citations, women scholars might also be less represented in textbooks (Cassese, Bos, and Duncan 2012), course syllabi (Hardt et al. 2017; Colgan 2017), and less central in citation networks (Maliniak, Powers, and Walter 2013). While conventional wisdom suggests that filling in the leaky pipeline will reduce these "Matthew effects", our analyses show that women's work is less likely to be cited by men and mixed gender author teams, even in subfields populated predominantly by women scholars (e.g., politics and gender). While greater gender diversity improves the chances for proper attribution of ideas to female scholars, gender gaps in citations remain.

Our study does not consider the sociological processes that drive gender citation gaps in detail, but we can provide some thoughts about how to address "Matilda effects" in citation networks. First, the development of recent tools (Sumner 2018) to calculate gender balance in syllabi can also be used in constructing journal article bibliographies. While the overall percentage of citations may not identify what work by women could be invisible in a research field, the data can suggest a reasonable baseline for the percentage of works that should involve female contributors. Some journals have explicit policies that ask authors to explain a lack of citations to work by women and other minority groups prior to publication (e.g., International Studies Quarterly). Second, the failure to cite work by women often stems from the overall lack of gender diversity in a discipline. Articles in Econometrica cite few studies by women because women do not study econometrics at the same rate as they study other social science topics. ${ }^{25}$ Mentoring programs such as CeMENT, Journeys in World Politics, and Visions in Methodology can be useful for recruiting women into male-dominated fields and improving chances for publication success in highly ranked journals (Blau et al. 2010; Barnes and Beaulieu 2017). Third, the lack of gender and racial diversity generates long-term costs to academic disciplines (Achen 2014; Mershon and Walsh 2016). Most notable is

25 For a discussion of this issue in political methodology, see Shannon (2014). 
the truncation of ontological and epistemological perspectives. ${ }^{26}$ In addition to marginalizing topics about race and gender (Achen 2014; McClain et al. 2016), methodological perspectives focus on quantitative rather than qualitative approaches, which can exclude work by women and minority scholars from the most highly ranked disciplinary journals (Teele and Thelen 2017). Fourth, the processes that create gender citation gaps also hinder the advancement of women in social science fields. Women are less likely than their male colleagues to be invited to give talks at top research institutions (Nittrouer et al. 2018). ${ }^{27}$ Higher standards can be imposed on women in the research process, leading to tougher barriers for getting grants (Bornmann, Mutz, and Daniel 2007), longer review times (Hengel 2017), ${ }^{28}$ and lower publication quantities (Hesli and Lee 2011). Citation gender gaps may be driven by the lack of citations for senior women's work (Roberts, Stewart, and Nielsen 2017), which helps to explain why our study uncovers few temporal changes in citation patterns even though more women are earning PhDs in the social sciences in 2017 than in 2006.

The positive news from our study is that women scholars are receiving more recognition for their work in the form of journal citations as their disciplines and subfields become more gender diverse. Overcoming the remaining "Matilda effects" will require raising awareness of the issue and creating a gender blind environment for what constitutes the scientific core of the social sciences.

\section{Supplementary material}

For supplementary material accompanying this paper, please visit

https://doi.org/10.1017/pan.2018.12.

\section{References}

Achen, Christopher. 2014. Why do we need diversity in the political methodology society? The Political Methodologist 21(2):25-29.

APSA. 2017. APSA Membership Dashboard. Washington, D.C.: American Political Science Association.

Aksnes, Dag W., Kristoffer Rorstad, Fredrik Piro, and Gunnar Sivertsen. 2011. Are female researchers less cited? A large-scale study of Norwegian scientists. Journal of the American Society for Information Science and Technology 62(4):628-636.

Barnes, Tiffany D., and Emily Beaulieu. 2017. Engaging women: Addressing the gender gap in women's networking and productivity. PS: Political Science \& Politics 50(2):461-466.

Beaudry, Catherine, and Vincent Larivière. 2016. Which gender gap? Factors affecting researchers' scientific impact in science and medicine. Research Policy 45(9):1790-1817.

Blau, Francine, Rachel Croson, Janet Currie, and Donna K. Ginther. 2010. Can mentoring help female assistant professors? Interim results from a randomized trial. American Economic Review 100(2):348-352.

Borrego, Ángel, Maite Barrios, Anna Villarroya, and Candela Ollé. 2010. Scientific output and impact of postdoctoral scientists: A gender perspective. Scientometrics 83(1):93-101.

Bornmann, Lutz, Rudiger Mutz, and Hans-Dieter Daniel. 2007. Gender differences in grant peer review: A meta-analysis. Journal of Informetrics 1(3):226-238.

Cameron, Elissa Z., Angela M. White, and Meeghan E. Gray. 2016. Solving the productivity and impact puzzle: Do men outperform women, or are metrics biased? BioScience 66(3):245-252.

Carter, T. Edison, Thomas E. Smith, and Philip J. Osteen. 2017. Gender comparisons of social work faculty using h-index scores. Scientometrics 111(3):1547-1557.

Cassese, Erin C., Angela L. Bos, and Lauren E. Duncan. 2012. Integrating gender into the political science core curriculum. PS: Political Science \& Politics 45(2):238-243.

26 In an analysis of citations in international relations journals, Roberts, Stewart, and Nielsen (2017) show that men and women authors use distinct words and study different topics (e.g., women authors are more likely to use the words gender, children, and human rights). They also show that once you apply advanced matching techniques, the gender gap in citations is even larger than previously estimated (16 fewer citations per article for women) and that this gap is driven mostly by the lack of citations to work by senior women.

27 This study examines colloquium talks at the top 50 U.S. universities in six disciplines, including political science and sociology. Men gave twice as many talks as women (69\% versus $31 \%)$.

28 Hengel (2017) applies readability tests to abstracts of over 9,000 articles in four economics journals. She finds that women's abstracts score higher on readability metrics and that these scores improve over time (but only for women scholars). She also finds that women's papers spend six months longer in peer review in Econometrica than men's papers. 
Chamberlain, Scott, Carl Boettiger, Ted Hart, and Karthik Ram. 2016. Rcrossref: Client for Various "CrossRef" APIs (version 0.6.0). https://cran.r-project.org/web/packages/rcrossref/index.html.

Colgan, Jeff. 2017. Gender bias in international relations graduate education? New evidence from syllabi. PS: Political Science \& Politics 50(2):456-460.

Corley, Elizabeth A., and Meghna Sabharwal. 2010. Scholarly collaboration and productivity patterns in public administration: Analysing recent trends. Public Administration 88(3):627-648.

Di Vaio, Gianfranco, Daniel Waldenström, and Jacob Weisdorf. 2012. Citation success: Evidence from economic history journal publications. Explorations in Economic History 49(1):92-104.

Diamond, Arthur M. 1986. What is a citation worth? The Journal of Human Resources 21(2):200-215.

Dion, Michelle. 2014. An effort to increase women's participation: The visions in methodology initiative. The Political Methodologist 21(2):6-9.

Dion, Michelle L., and Sara McLaughlin Mitchell. 2012. Gender, participation, and citations: Comparing peace science, political methodology, state politics, and IPE conferences. Poster presented at the 2012 Peace Science Society Meeting, Savannah, GA.

Dion, Michelle L., Jane Lawrence Sumner, and Sara McLaughlin Mitchell. 2018. Replication Data for: Gendered Citation Patterns across Political Science and Social Science Methodology Fields, doi:10.7910/DVN/R7AQT1, Harvard Dataverse, V1, UNF:6:CInBeM5eziTIPGjBVTpr4A==.

Ferber, Marianne A. 1986. Citations: Are they an objective measure of scholarly merit? Signs 11(2):381-389.

Ferber, Marianne A. 1988. Citations and networking. Gender \& Society 2(1):82-89.

Ferber, Marianne A., and Michael Brün. 2011. The gender gap in citations: Does it persist? Feminist Economics 17(1):151-158.

Flaherty, Colleen. 2016. "Tenure, Women and Economics." Inside Higher Ed. December 14. https://www.insidehighered.com/news/2016/12/14/new-study-finds-gender-gaps-tenure-rates-andcareer-paths-economics.

Fowler, James H., and Dag W. Aksnes. 2007. Does self-citation pay? Scientometrics 72(3):427-437.

Geraci, Lisa, Steve Balsis, and Alexander J. Busch. 2015. Gender and the H index in psychology. Scientometrics 105(3):2023-2034.

Ghiasi, Gita, Vincent Larivière, and Cassidy R. Sugimoto. 2016. Gender differences in synchronous and diachronous self-citation. In STI2016-Proceedings of the 21st international conference on science and technology indicators, ed. I. Rafols, J. Molas-Gallart, E. Castro-Martínez, and R. Woolley. Valencia: Editorial Universitat Politècnica de València, pp. 844-851.

Håkanson, Malin. 2005. The impact of gender on citations: an analysis of college \& research libraries, journal of academic librarianship, and library quarterly. College \& Research Libraries 66(4):312-323.

Hardt, Heidi, Hannah Kim, Philippe Meister, and Amy E. Smith. 2017. Diversity by the book: Gender representation in political science graduate training. Paper presented at the Annual Convention of the Midwest Political Science Association, Chicago, IL.

Hengel, Erin. 2017. "Publishing While Female.” Working paper, available at www.erinhengel.com/research/.

Hesli, Vicki L., and Jae Mook Lee. 2011. Faculty research productivity: Why do some of our colleagues publish more than others? PS: Political Science and Politics 44(2):393-408.

Hopkins, Allison L., James W. Jawitz, Christopher McCarty, Alex Goldman, and Nandita B. Basu. 2013. Disparities in publication patterns by gender, race and ethnicity based on a survey of a random sample of authors. Scientometrics 96(2):515-534.

Hutson, Scott R. 2006. Self-citation in archaeology: Age, gender, prestige, and the self. Journal of Archaeological Method and Theory 13(1):1-18.

Hur, Hyungjo, Maryam A. Andalib, Julie A. Maurer, Joshua D. Hawley, and Navid Ghaffarzadegan. 2017. Recent trends in the U.S. behavioral and social sciences research (BSSR) workforce. PLOS ONE 12(2): e0170887.

King, Molly M., Carl T. Bergstrom, Shelley J. Correll, Jennifer Jacquet, and Jevin D. West. 2016. Men set their own cites high: Gender and self-citation across fields and over time. arXiv:1607.00376v2 [physics.soc-ph].

Knobloch-Westerwick, Silvia, Carroll J. Glynn, and Michael Huge. 2013. The matilda effect in science communication: An experiment on gender bias in publication quality perceptions and collaboration interest. Science Communication 35(5):603-625.

Leahey, E., J. L. Crockett, and L. A. Hunter. 2008. Gendered academic careers: Specializing for success? Social Forces 86(3):1273-1309.

Leahey, Erin, Christine M. Beckman, and Taryn L. Stanko. 2017. Prominent but less productive: The impact of interdisciplinarity on scientists' research. Administrative Science Quarterly 62(1):105-139.

Long, J. Scott. 1992. Measures in sex differences in scientific productivity. Social Forces 71(1):159-178.

Maliniak, Daniel, Ryan Powers, and Barbara F. Walter. 2013. The gender citation gap in international relations. International Organization 67(4):889-922.

McClain, Paula D., Gloria Y. A. Ayee, Taneisha N. Means, Alicia M. ReyesBarriéntez, and Nura A. Sediqe. 2016. Race, power, and knowledge: Tracing the roots of exclusion in the development of political science in the United States. Politics, Groups, and Identities 4(3):467-482. 
Mead, Lawrence M. 2010. Scholasticism in political science. Perspectives on Politics 8(2):453-464.

Mershon, Carol, and Denise Walsh. 2016. Diversity in political science: Why it matters and how to get it. Politics, Groups, and Identities 4(3):462-466.

Mitchell, Sara McLaughlin, and Vicki L. Hesli. 2013. Women don't ask? Women don't say no? Bargaining and service in the political science profession. PS: Political Science \& Politics 46(2):355-369.

Mitchell, Sara McLaughlin, Samantha Lange, and Holly Brus. 2013. Gendered citation patterns in international relations journals. International Studies Perspectives 14(4):485-492.

Nielsen, Mathias Wullum. 2016. Gender inequality and research performance: Moving beyond individual-meritocratic explanations of academic advancement. Studies in Higher Education 41(11):2044-2060.

Nittrouer, C. L., M. R. Hebl, L. Ashburn-Nardo, R. C. E. Trump-Steele, D. M. Lane, and V. V. Valian. 2018. Biases against female colloquium speakers at top universities. Proceedings of the National Academy of Sciences of the United States of America 115(1):104-108.

Nosek, Brian A., Jesse Graham, Nicole M. Lindner, Selin Kesebir, Carlee Beth Hawkins, Cheryl Hahn, and Kathleen Schmidt et al. 2010. Cumulative and career-stage citation impact of social-personality psychology programs and their members. Personality and Social Psychology Bulletin 36(10):1283-1300.

Østby, Gudrun, Håvard Strand, Ragnhild Nordås, and Nils Petter Gleditsch. 2013. Gender gap or gender bias in peace research? Publication patterns and citation rates for Journal of Peace Research, 1983-2008. International Studies Perspectives 14(4):493-506.

Powell, A., T. M. Hassan, A. R. J. Dainty, and C. Carter. 2009. Exploring gender differences in construction research: a european perspective. Construction Management and Economics 27(9):803-807.

Reece-Evans, Linsay. 2010. Gender and citation in two LIS E-Journals: A bibliometric analysis of LIBRES and information research. LIBRES 20(1):1-18.

Roberts, Margaret E, Brandon M. Stewart, and Richard Nielsen. 2017. Matching methods for high-dimensional data with applications to text. Working paper, available at http://www.margaretroberts.net/.

Rossiter, Margaret W. 1993. The Matthew Matilda effect in science. Social Studies of Science 23(2):325-341.

Shannon, Megan. 2014. Barriers to women's participation in methodology: Graduate school and beyond. The Political Methodologist 21(2):2-5.

Slyder, Jacob B., Beth R. Stein, Brent S. Sams, David M. Walker, B. Jacob Beale, Jeffrey J. Feldhaus, and Carolyn A. Copenheaver. 2011. Citation pattern and lifespan: A comparison of discipline, institution, and individual. Scientometrics 89:955-966.

Stack, Steven. 2002. Gender and scholarly productivity: The case of criminal justice. Journal of Criminal Justice 30(3):175-182.

Sumner, Jane Lawrence. 2018. The gender balance assessment tool (GBAT): A web-based tool for estimating gender balance in syllabi and bibliographies. PS: Political Science \& Politics 51(2):396-400.

Symonds, Matthew R. E., Neil J. Gemmell, Tamsin L. Braisher, Kylie L. Gorringe, and Mark A. Elgar. 2006. Gender differences in publication output: Towards an unbiased metric of research performance. Edited by Tom Tregenza. PLOS ONE 1(1):e127.

Teele, Dawn Langan, and Kathleen Thelen. 2017. Gender in the journals: Publication patterns in political science. PS: Political Science \& Politics 50(2):433-447.

Wais, Kamil. 2016. Gender prediction methods based on first names with genderizeR. $R$ Journal 8(1):17-37.

Wais, Kamil, Nathan VanHoudnos, and John Ramey. 2016. genderizeR: Gender Prediction Based on First Names (version 2.0.0). https://cran.r-project.org/web/packages/genderizeR/index.html.

Ward, Kathryn B., Julie Gast, and Linda Grant. 1992. Visibility and dissemination of women's and men's sociological scholarship. Social Problems 39(3):291-298. 